\title{
MORPHOLOGICAL EVOLUTION OF THE GREAT YARMOUTH SANDBANK \& CHANNEL SYSTEM
}

\author{
Anna Bakare ${ }^{1}$, Richard Simons ${ }^{2}$, Jeremy Morley ${ }^{3}$ and Serge Guillas ${ }^{4}$
}

\begin{abstract}
This paper investigates the morphological history of a sandbank system from the $19^{\text {th }}$ century to the present and evaluates the applicability of a new data-driven method for morphological modelling that accounts for multi-dimensional spatial relationships. Trend analyses of point locations, profile transects and contours were carried out to investigate the morphological evolution of the domain, while the spatial regression model was used for modelling. Results from the trend analysis indicate there is a constant northern migration of the sandbank features. Furthermore the physical extents of the banks are increasing in the alongshore direction. Sandbank features are also observed to have recurring horizontal movement patterns, which occur on a multi-decadal periodicity. The lateral movement is seen to relate to changing bank configurations and coincide with channel formation and disappearance at the $10 \mathrm{~m}$ contour. Predictions with the spatial regression model show it represents the behaviour inherent in the data and system, demonstrated by the prediction RMSE being less than the mean seabed variability. In addition, the model predicts bed depth to an accuracy of $\pm 0.25 \mathrm{~m}$ on the top of the banks or where the gradient of the seabed is shallow. However, where there is a large change in depth over a short distance the prediction error is increased.
\end{abstract}

Keywords: sandbanks; Great Yarmouth; morphological evolution; data-driven statistical morphological modelling

\section{INTRODUCTION}

The study domain is the Great Yarmouth sandbank and channel system, located approximately fifteen kilometres offshore of the East Anglian coast, between Winterton-on-Sea and Benacre Ness. The area is bounded by WGS84 geographic grid coordinates $52.759 \mathrm{~N}, 1.644 \mathrm{E}$ and $52.392 \mathrm{~N}, 1.912 \mathrm{E}$ for the northwest and southeast corners respectively. The study site is characterised by dynamic tidal sandbanks and channels, which evolve at varying spatial and temporal time scales and is the subject of ongoing research. The sandbank features are characterised as tidal-dominated alternating headland ridges, which would have started as headland associated banner banks based on the categorisation by Dyer and Huntley, (1999). Although the short term evolutionary characteristics are known through the use of numerical modelling (HR Wallingford, 2002), the long-term evolution of the sandbanks is less well understood. Difficulties arise because of the non-linear interactions between the morphology and forcing conditions at large time scales, as well as the dynamic interaction between the morphological features themselves.

Understanding the long-term characteristics of the morphology and the association with natural and anthropogenic forcing conditions are important for effective management practices in this region, as the sandbanks and channels within the system are important economic resources. The banks provide a source of aggregates, are a host for offshore wind farms and act as natural barriers to dissipate the energy of large offshore storm waves approaching the shoreline. The channels provide navigable routes into the commercial ports of Great Yarmouth and Lowestoft.

Therefore, the aims of this study are as follows:

- Contribute to current understanding of the long-term evolution of the Great Yarmouth sandbank system, by exploring the morphological evolution from the $19^{\text {th }}$ century to the present.

- Assess the validity of a new data-driven statistical method in modelling and predicting the evolution of the features within the Great Yarmouth system.

To achieve the above, this study uses time series analysis methods to describe the evolution of the sandbanks and channel features, and uses the spatial regression model to predict the morphological evolution within the domain. Section 2 presents and discusses the current state of knowledge of the morphological evolution properties. Section 3 introduces the datasets and methods used in the analyses and modelling, where the results obtained are set out in Section 4. Section 5 discusses the results in the context of contributing to current understanding of the characteristics of the domain, and

\footnotetext{
${ }^{1}$ Department of Civil, Environmental and Geomatic Engineering, UCL, Gower St, London, WC1E 6BT, UK

${ }^{2}$ Department of Civil, Environmental and Geomatic Engineering, UCL, Gower St, London, WC1E 6BT, UK

${ }^{3}$ Centre for Geospatial Science, University of Nottingham, Sir Clive Granger Building, University Park, Nottingham, NG7 2RD, UK

${ }^{4}$ Department of Statistical Science \& Aon Benfield UCL Hazard Research Centre, UCL, Gower St, London, WC1E 6BT, UK
} 
evaluates the model applicability at this site, before concluding with a review of areas for further investigation.

\section{MORPHODYNAMICS OF THE GREAT YARMOUTH SYSTEM}

The sandbanks and channels within the study area are illustrated in Figure 1. Closest to the shoreline at approximately $2 \mathrm{~km}$ are Caister Shoal and Newcombe Sand, although, the northern tip of the latter is attached to Lowestoft Ness at the $10 \mathrm{~m}$ contour. Approximately $4 \mathrm{~km}$ from the shoreline and running from north to south are the banks of North, Middle and South Scroby, Corton and Holm Sands. North and Middle Cross Sands are the roughly parallel line of banks off Scroby Sands and are approximately $10 \mathrm{~km}$ from the shoreline. South Cross Sand, approximately $7 \mathrm{~km}$ from the shoreline is linked to Corton Sand at the $10 \mathrm{~m}$ contour. The lengths of the sandbank features range between $4 \mathrm{~km}$ and $15 \mathrm{~km}$ with widths of $1.5 \mathrm{~km}$ to $3 \mathrm{~km}$. The banks are in water $20 \mathrm{~m}$ deep and extend up to the sea surface with some parts presently being intertidal (Cooper et al., 2008). A number of channels run through the study area. The dominant channels include Caister, Yarmouth and Corton Roads, which connect into each other, parallel to the shoreline, and Barley Pickle between Scroby, Middle and South Cross Sands. The positions of the banks are considered to be fixed between these two channels because they cut into the underlying Pleistocene Crag which the banks sit on (Ibid.). There are a number of other channels that cross between the banks with depths of about 10-15m namely Stanford, Newcombe, Holm and Hewett Channels. The positions of these channels change in relation to the shifting banks as observed from qualitative assessment of historic nautical charts. These smaller channels have the characteristic of flood-ebb meander channels as found in estuaries (Ibid.).



Figure 1: Sandbanks and channel features within the study area.

\section{Paleo-geography}

The sandbank system is located on the North Sea shelf, which is about $150 \mathrm{~km}$ from east to west and $90 \mathrm{~km}$ from north to south extending approximately between England and the Netherlands (Cooper et al., 2008). The origin of the Great Yarmouth Banks is attributed to the erosion of the Norfolk and Suffolk shoreline during the Holocene transgression. Due to the location of the banks, i.e. $4-8 \mathrm{~km}$ from the coastline, they are considered to be recent geological features and have a shorter evolution period (Ibid.). A plausible cause for the present form of the banks is the tidal flow characteristics around the east coast of England which aligns with the shoreline orientation. This brings about meandering tidal flow patterns, tidal ebb and flood channels and, consequently, 
development of sandbanks at intersecting locations (Ibid.). The flow patterns described above coincide with circulation patterns observed by Robinson, (1966) in field studies using drogue runs, tracers and current meters.

Tides

The tides on the east coast of England and in the study area are semidiurnal. Semidiurnal North Sea tides progress cyclonically within the basin and the largest amplitudes occur along the east coast of England and the German Bight (Huthnance, 1991). The tides within the study area are meso-tidal with a range of $2.6 \mathrm{~m}$ and $1.4 \mathrm{~m}$ for the mean spring and neap tides respectively at Winterton-on-Sea (Horrillo-Caraballo and Reeve, 2008). At Lowestoft, observed mean tidal ranges are $1.9 \mathrm{~m}$ and $1.1 \mathrm{~m}$ for the spring and neap tides respectively (Ibid.). The tidal current velocities vary spatially across the domain. Maximum tidal speeds observed for the area beyond Corton Shoal, approximately $6 \mathrm{~km}$ offshore, are about $1.75 \mathrm{~m} / \mathrm{s}$ on spring tides and $1.23 \mathrm{~m} / \mathrm{s}$ on neap tides (Robinson, 1966). Further inshore in the Yarmouth Roads maximum speeds that occur are $1.18 \mathrm{~m} / \mathrm{s}$ and $0.77 \mathrm{~m} / \mathrm{s}$ for the spring and neap tides respectively (Ibid). In the study area the flood stream runs approximately north to south, and the ebb flows roughly south to north. Asymmetries are observed between the flood and ebb tidal flows, which also vary with the type of the tide (Robinson, 1966, Huthnance, 1973). However there is an overall ebb dominance and a tidal residual in a north to northeast direction (Cooper et al., 2008).

\section{Waves}

In the North Sea, average and extreme wave heights are generally seen to decrease southwards and inshore (Huthnance, 1991). The study area is subjected to waves that approach predominantly from the north and northeast. This is the direction of the longest fetch, with the highest waves coming from this direction. Results generated from hind-casting wind data for a period between 1986 and 1999 showed that approximately $40 \%$ of waves were below $1 \mathrm{~m}$ and $76 \%$ of waves were below $2 \mathrm{~m}$ (Pye and Blott, 2006). Calculated extreme wave statistics based on a Weibull distribution for wave height observations obtained from the UK Meteorological Office showed that the 1 in 100 year height is approximately $8 \mathrm{~m}$. The calculated exceedance statistics relate to what is identified by Pye and Blott, (2006) where the 1 in 100 and 1 in 1 year are 7.3-7.8m and 5m respectively, for waves approaching from a north to northeast direction. Wave heights for the same exceedance events from other directions are 5.4-6.7m and $4.3 \mathrm{~m}$ respectively. For sandbanks in the Dunwich-Sizewell area, observations with Waverider buoys on either side of the banks showed that the sandbanks acted to break large incident waves. This offered some sheltering to the shoreline particularly during storm conditions. However, under moderate wave conditions the sandbanks did not significantly reduce the wave energy that approached the shoreline (Ibid.).

\section{Storm Surge}

Meteorological conditions can act to modify observed tidal heights causing a surge which can be an increase or reduction of the normal sea level. Much of the Southern North Sea is relatively shallow therefore atmospheric pressure and strong winds are able to force currents and modify sea surface levels (Huthnance, 1991). The North Sea is prone to frequent surge events that are generally less than $1 \mathrm{~m}$ with a surge of greater than $5 \mathrm{~m}$ occurring less frequently. There have been a number of major surge events and associated effects within the study region. Major surge events are noted to have occurred in 1817, 1883, 1897, 1912, 1928, 1938, 1949, 1953, 1976, 1978, 1982 and 1993 (Pye and Blott, 2006; HR Wallingford, 2002).

\section{Morphology and Morphodynamic Regime}

The sandbanks in the study area are asymmetrical in cross-section with the steeper leeward slope oblique to the direction of the peak tidal flow and net sand transport (Kenyon and Cooper, 2005; Stride, 1988; Dyer and Huntley, 1999). The orientation of the shoreline at a regional scale acts to modify the flow in the nearshore zone. Therefore the tidal flow runs from west-northwest to eastsoutheast along the North Norfolk coast and turns in relation to the coastline to flow north-northeast to south-southwest along the Suffolk coast (Cooper et al., 2008).

Previous studies indicate that the Great Yarmouth banks are highly mobile in the north-south direction with far less migration laterally. This was interpreted from northward dipping internal reflectors identified on South Cross Sand, indicating migration in the same direction (Cooper et al., 2008). This characteristic is considered to be due to the positions of the deeper channels that are fixed 
in position, namely The Roads and Barley Picle (Ibid.). Stronger flows are observed within these channels and are considered to be a factor in confining the lateral movement of the banks. Nevertheless some lateral movement in bank position does occur as identified by Dolphin et al., (2007). From assessments of historic bathymetric data for Newcombe Sand, Dolphin et al., (2007) identified bank evolution patterns whereby the bank shifted between 'deltaic' and 'elongate' states, which involved a lateral movement in the bank shape. Evolution of the Great Yarmouth banks is predominantly considered to be related to the tidal residual flow. However Dolphin et al., (2007) and Thurston et al., (2009) propose that storm events act as catalysts to induce a large change in the form of the sandbanks in a short space of time from evidence observed on Newcombe Sand (Dolphin et al., 2007).

\section{DATA AND METHODOLOGY}

The dataset used for analysis and modelling is a time series of seabed depths, and analysis at this site is carried out at a decadal time scale dating from approximately 1840 to 2006. Trend analysis is used to assess the qualitative geomorphological properties of the domain, particularly for the sandbanks Scroby, Holm, North and Middle Cross and South Cross Sands, and channel features The Roads and Barley Picle. Only these features were assessed as they are dominant features in the domain and are consistently present. The spatial regression model is used to investigate its applicability to real datasets and determine if it is able to identify and generate predictions of real macro scale morphological behaviour at approximately a decadal time scale.

\section{Bathymetric Dataset}

A bathymetric dataset digitised from 36 historic Admiralty navigation charts is used in this study. Although the charts and recorded depths would have originally been surveyed to different vertical datums, these have been corrected to Chart Datum (CD). In addition the spatial orientation of the charted domain was fixed to true north. The charts would also have been compiled from multiple surveys, which used different methods to derive the depth. Checks on the accuracy of bed levels for the historic charts by Reeve et al., (2001) indicate an accuracy of $\pm 0.5 \mathrm{~m}$. Further checks against available original survey soundings for localised areas obtained through the Civil Hydrography Program indicate an accuracy of $\pm 1.5 \mathrm{~m}$. For the purpose of this study, and because of the large spatial and temporal extent of the domain, the accuracy of the dataset is considered to be acceptable. The digitised and corrected depth levels were interpolated into a surface with a grid cell resolution of 200m, using the Kriging method (Reeve et al., 2008). The centroid of each cell was derived and assigned the depth value of the respective cell, which was used in further analysis, after removing the points that were on land.

\section{Trend Analyses}

The sandbanks and channels are considered to be highly mobile, so it is useful to understand the migration and evolution characteristics of the features. The time series of feature depths and movement of feature contours were evaluated for the selected features, where the depth is taken relative to a bed datum. Point locations on the selected features were used to assess how the depth of the feature at that position varied. Time series of profile transects were used to provide an indication of the spatial variation of the features in the cross-shore and alongshore directions. The assessment point locations and profile transects are illustrated in Figure 2. Assessment points were situated on the middle and nearshore and offshore flanks of the feature, while four profiles were applied, two in the cross-shore and alongshore directions each (Figure 2). 


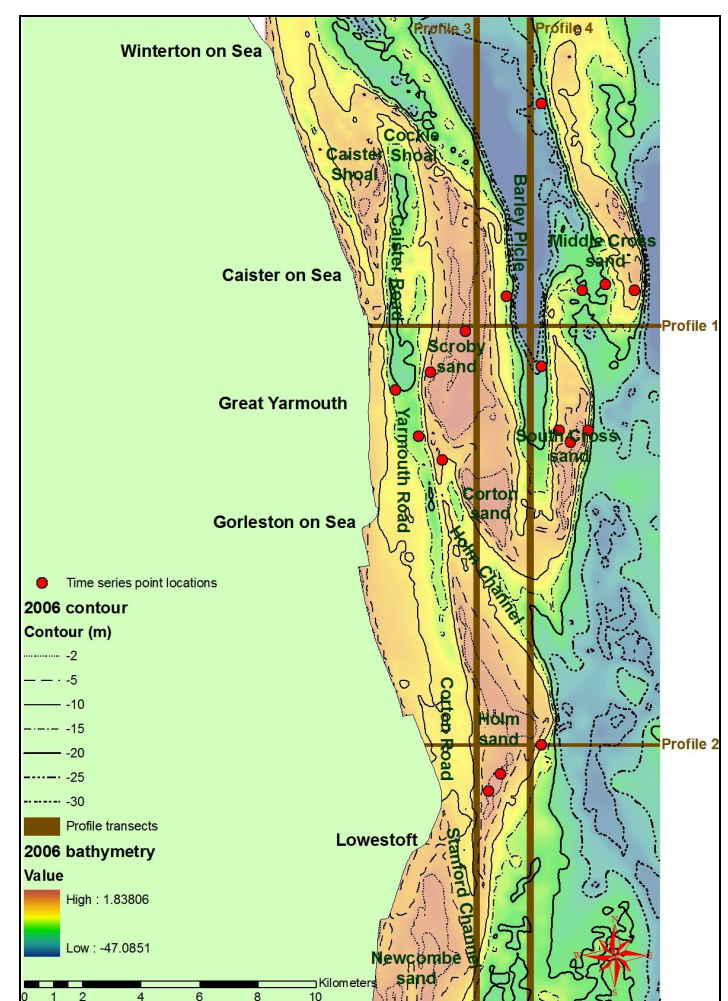

Figure 2: Study area with profile transects and feature assessment points.

The study set out to replicate contour analyses undertaken by Cloet, (1963), who assessed the movement of the northern and southern extents of selected contours. The aim with this analysis was to provide further information on the spatial variation of the features. The analysis first involved interpolating the input points into surfaces at a $100 \mathrm{~m}$ resolution, from which contours were generated at one metre intervals. The interpolation and contouring procedure was undertaken using functionality from ESRI ArcGIS 9.3. From the resulting contours, the northern and southern extents of the $10 \mathrm{~m}$ contour for the sandbank features, $15 \mathrm{~m}$ for The Roads and $20 \mathrm{~m}$ for Barley Picle, were recorded and the movement evaluated. The assessed contours represent the extents of the features that were still variable, where any movement of the contour indicated a change in the bank structure.

A check was carried out to assess the accuracy of the interpolated surfaces and contours in relation to the original input datasets. These were also compared against depth soundings for the year 2000 EA9 resurvey area under the Civil Hydrography Program (CHP), to determine how closely the contours related to the true input values. Results demonstrate that the interpolation and contour values represent the depths to within an average accuracy $\pm 1.5 \mathrm{~m}$ based on the mean absolute error. Therefore the interpolation and contour datasets represent the depths to a reasonable accuracy and are acceptable for application in the contour analysis.

\section{Spatial Regression Model}

A data-driven statistical model is used to model the morphological evolution characteristics of the Great Yarmouth system at approximately a decadal time scale. It applies a novel statistical method that accounts for spatial association across a domain in investigating the evolution characteristics of the system. The implicit characteristics of the model are such that two-dimensional (2D) spatial behaviour inherent in the time-series datasets are encapsulated and used in the modelling process. The model achieves this by representing the spatial behaviour in both the $\mathrm{X}$ and $\mathrm{Y}$ directions simultaneously as a time series of surface functions. It then derives an expression of how the successive surfaces evolve through the time series by first generating a series of change surfaces between consecutive steps. Regression analysis that minimises the error variance in the time-lagged covariance matrix for the whole domain is used to derive an estimate of the rate of change across the domain. The resulting regression function is then used to estimate future changes and derive a prediction based on the last observable surface. The spatial regression model is defined in Eq. 1. 


$$
Y=\int_{D} g(s) X(s) d s+\varepsilon
$$

where $g$ is a weight function of the spatial-temporal evolution that needs to be estimated as a function of the random surface of observations $X . s$ are observations in the polygonal domain $(D)$ and $\varepsilon$ is the noise, a real random variable centred and uncorrelated with $X . Y$ is the response variable and is the height value at a certain location.

Bakare et al., (2009) describe the characteristics of the model in more detail and set out results obtained in applying the model to idealised morphological scenarios with known behaviour and evolution properties. They showed that the model is able to identify evolution characteristics such as feature migration and periodic behaviour, while maintaining the form and structure of the features. In addition the model is able to generate accurate predictions represented by root mean square error measures of $\leq 0.1 \mathrm{~m}$, with the error being less than the observed variability in the time series.

\section{RESULTS}

\section{Profile Transects Interpretation}

A summary of the feature evolution properties identified from the profile transects is given below for each profile. These contribute to interpreting the morphological properties for each respective feature.

Profile 1

The width of the nearshore channel at Caister Road gets wider as Scroby Sand's nearshore flank steepens. Scroby Sand predominantly seems fixed in the cross-shore axis within the time frame of the data but is variable in depth. It has been proposed that Scroby Sand is confined by the nearshore channel (The Roads) and the offshore channel (Cooper et al., 2008). It would seem from the time series along this profile that this is the case. However, it is not the same for North and Middle Cross Sand which varies in the cross-shore direction and depth along this profile. Prior to 1977 this feature was confined by Barley Picle in the extent it moved shoreward, but after this time it encroaches into the channel as described above.

\section{Profile 2}

The onshore movement of Holm Sand is predominantly confined by Lowestoft North Road and there are no observable features to limit offshore movement apart from deeper offshore depths. There is a periodic pattern of channel formation and disappearance on the offshore flank of Holm Sand, which is on a multi-decadal cycle that coincides with a shoreward migration of the feature flank. This then migrates offshore as the offshore channel disappears. Changes in the height of Holm Sand coincide with the altering width of the bank in the cross-shore direction, suggesting that although a flank may migrate, the sediment remains within the bank altering the depth.

Profile 3

There is a northward migration of the sandbank features along this profile although the migration speed is not consistent. However, Lowestoft North Road acts as a barrier to limit the northward migration of Newcombe Sand. There is a re-occurring pattern whereby there are multiple channels between Scroby Sand and the southern extent of the profile, which then disappear with subsequent changes on Holm Sand.

\section{Profile 4}

Once again, there is an observed northward migration of the bank features particularly South Cross Sand. In addition there is a pattern where a shoal is generated northwards of Holm Sand, which then decreases in size as South Cross Sand increases in size.

\section{Scroby Sand}

Based on the $10 \mathrm{~m}$ contour movement derived from the time series dataset Scroby Sand demonstrates a northward migration. In addition to the northern migration the bank pivots on the longitudinal axis so that the southern extent periodically is positioned offshore and then migrates onshore. When the southern $10 \mathrm{~m}$ extent of Scroby Sand is positioned offshore, then the bank is separate from Holm Sand at this contour. As the bank pivots towards the shoreline it joins the $10 \mathrm{~m}$ contour of Holm Sand. This pattern is observed to occur at least twice in the time series. Figure 3 illustrates this behaviour with the positions of the $10 \mathrm{~m}$ contour for the respective banks. 
Depth changes for the assessment points on Scroby Sand (Figure 4) show the offshore flank has the greatest variability with a range of up to $20 \mathrm{~m}$ in depth. This compares to a range of about $15 \mathrm{~m}$ and $12 \mathrm{~m}$ for the middle and nearshore locations respectively. A multi-decadal periodicity to the depth variation is observed at the offshore location; however there is no association with the nearshore and middle points (Figure 4). The time series of sediment volume shows a constant and consistent growth rate for this feature based on a plane depth at $15 \mathrm{~m} \mathrm{CD}$ (Figure 4). Qualitatively the variability in the sediment volume time series primarily relates to the depth variability for the middle assessment point for the feature (Figure 4). It is observed that an increase in the sediment volume for the sandbank is represented as decrease or shoaling of the sandbank depth. Therefore, the increasing sediment volume associated with this feature demonstrates a sediment source, with the feature acting as a local sink.

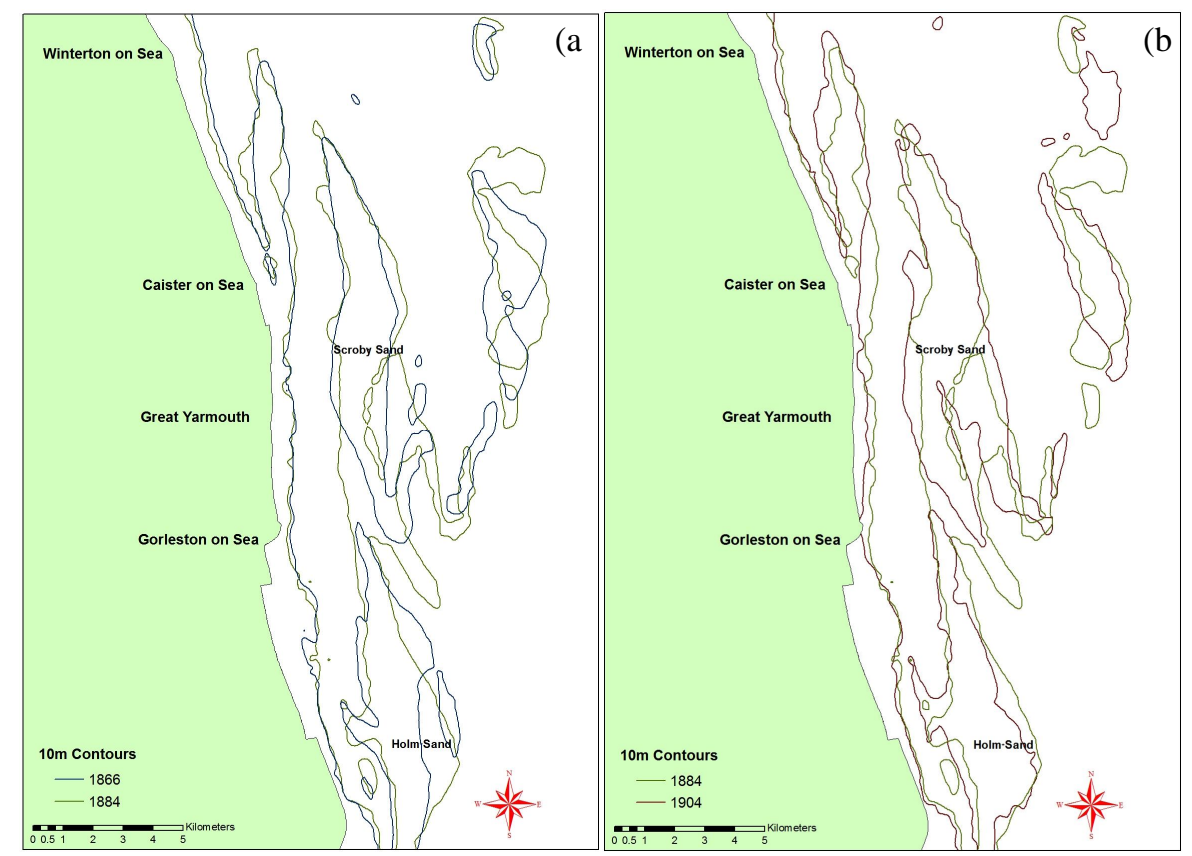

Figure 3: Movement of the $10 \mathrm{~m}$ contour for Scroby Sand, Holm Sand and Cross Sand, (a) time steps 1866 and 1884 and (b) time steps 1884 and 1904.

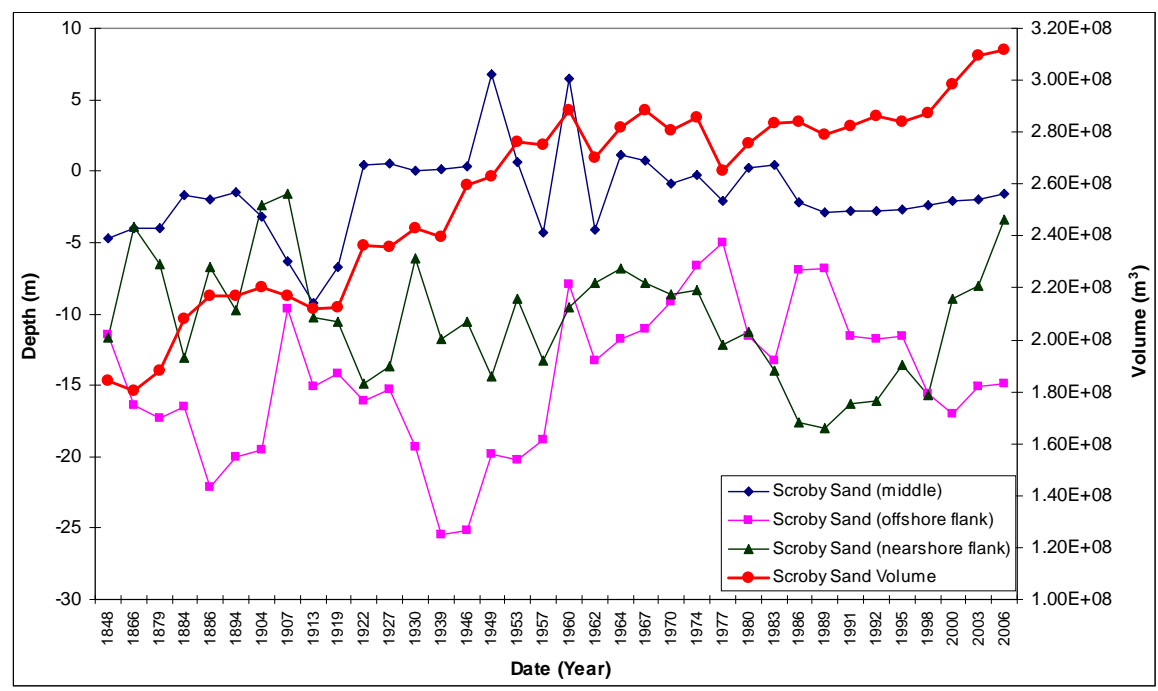

Figure 4: Time series of bed depth and sediment volume for Scroby Sand.

\section{Holm Sand}

The northern extent of Holm Sand's $10 \mathrm{~m}$ contour is seen to migrate northwards, whereas the southern extent is predominantly connected to the same contour projecting off the shoreline at Lowestoft North Road. This bank is not seen to pivot on an axis as described for Scroby Sand. 
However, as noted previously the northern extent does merge with the same contour from Scroby Sand as it pivots towards the shoreline.

Similar to Scroby Sand the time series plot for the assessment points on this feature show the offshore location has the most variability (Figure 5), with an observable periodicity to the variation. The sediment volume time series based on a plane depth at $15 \mathrm{~m}$ (CD) is included in Figure 5. It illustrates an increase in volume through the time series, although at a much smaller rate than for Scroby Sand (Figure 4). A trend is observed in the variability of the volume time series, where the pivot point is approximately at 1939 (Figure 5). Prior to 1939 the volume observations are seen to be at a smaller baseline and after which, the baseline increases. After 1939, there is also a periodic increase and decrease in the volume. For example between 1939 and 1980, the volume increases and decreases to a low point at 1980. After 1980, there is again an increase with the volume decreasing by the end of the time series in 2006. The periodicity in the volume measurements occurs at approximately a 40-year cycle; however the pattern for the offshore depth variability occurs at a 50year cycle. Figure 5 also indicates that the variability in the volumetric time series coincides with changes on primarily the offshore flank and to a lesser the extent the nearshore and middle points.

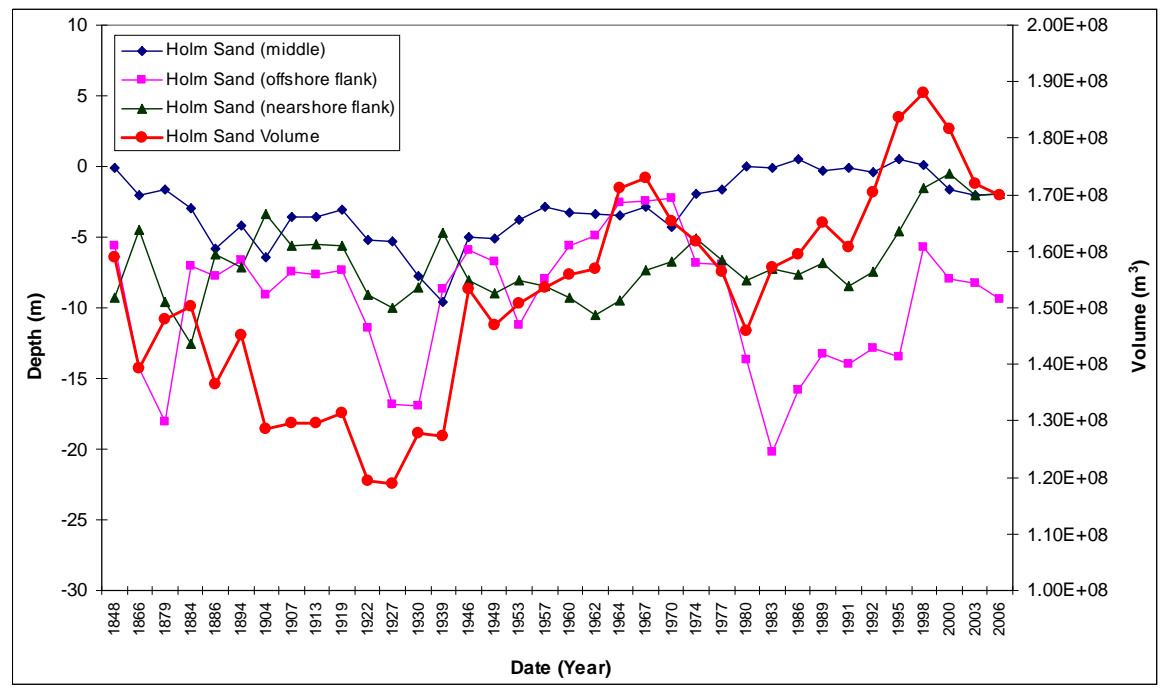

Figure 5: Time series of bed depth and sediment volume for Holm Sand.

\section{North and Middle Cross Sand}

North and Middle Cross Sands which are commonly linked at the $10 \mathrm{~m}$ contour are seen to migrate northwards as identified for Scroby and Holm Sands. In addition the feature at the $10 \mathrm{~m}$ contour pivots about its longitudinal axis so that the northern extent periodically moves onshore and offshore. However Barley Picle is constant and acts to limit the shoreward migration of the feature. In the depth time series (Figure 6), the offshore flank again has the greatest range at over 20m, where the nearshore and middle locations have a range of about $15 \mathrm{~m}$. The time series of sediment volume based on a plane depth at $24 \mathrm{~m}$ (CD) shows that there is a periodic increase and decrease in the sediment volume (Figure 6). The first phase is observed between the start of the time series and approximately 1940, which is approximately a 90-year period. The second phase is observed between 1940 and the end of the time series, which is a shorter, approximately 70-year period. Qualitatively the volumetric time series pattern relates to that observed for the middle and nearshore depth variability (Figure 6). However a small time shift is observed in the start and end of the phase, where the maximum depth with the end of the first period occurs between 1940 and 1950 for the depth, compared with 1940 for the sediment volume. 


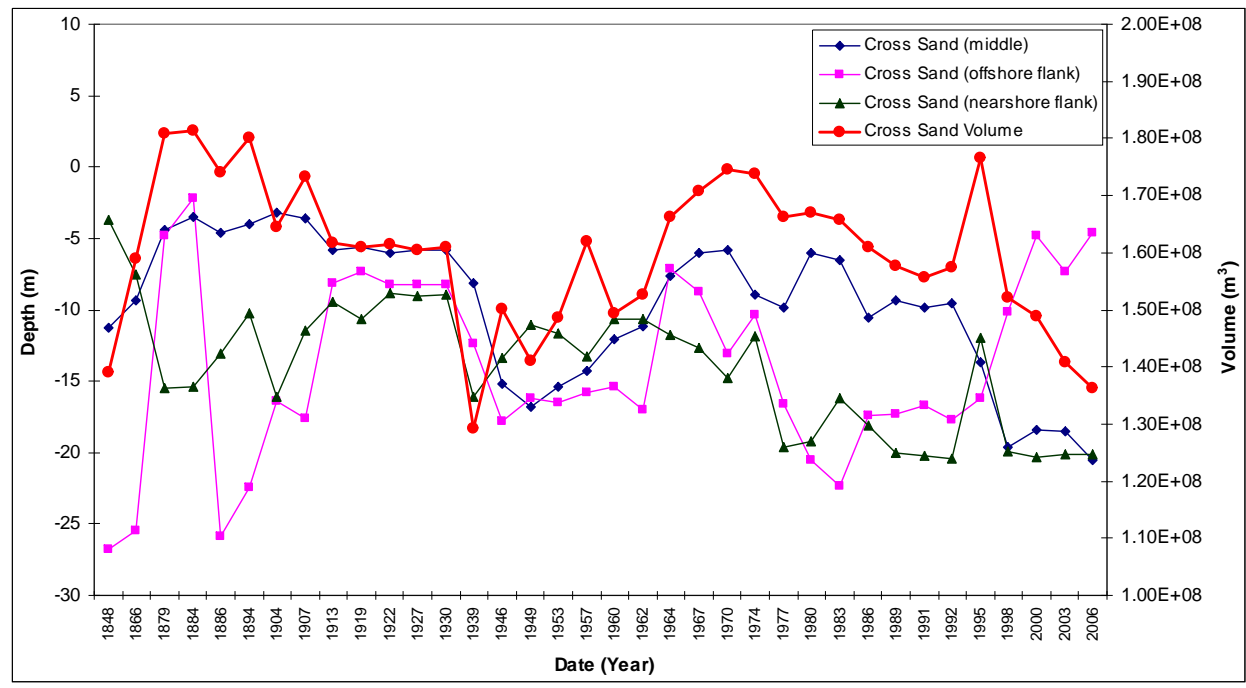

Figure 6: Time series of bed depth and sediment volume for North and Middle Cross Sand.

\section{South Cross Sand}

The morphology of South Cross Sand evolves in relation to changes on Scroby Sand. In historic maps, South Cross Sand is seen to project out to the southeast off the same $10 \mathrm{~m}$ contour as Scroby Sand. Analysis of the $10 \mathrm{~m}$ contour between the start and end of the time series show that the northern extent of the sandbank moves to the northeast whereas the southern extent moved southward. The depth range for the assessment points are similar, which differs from observations made on the other sandbank features. The sediment volume time series observed for this feature (Figure 7) demonstrates an initial period where there is a decrease in the sediment volume up to approximately 1940. Beyond this date the volume steadily increases up to the end of the time series, except for decrease between 1992 and 1995 (Figure 7). Qualitatively the decrease in sediment volume for this feature coincides with the increase in depth described for the assessment locations.

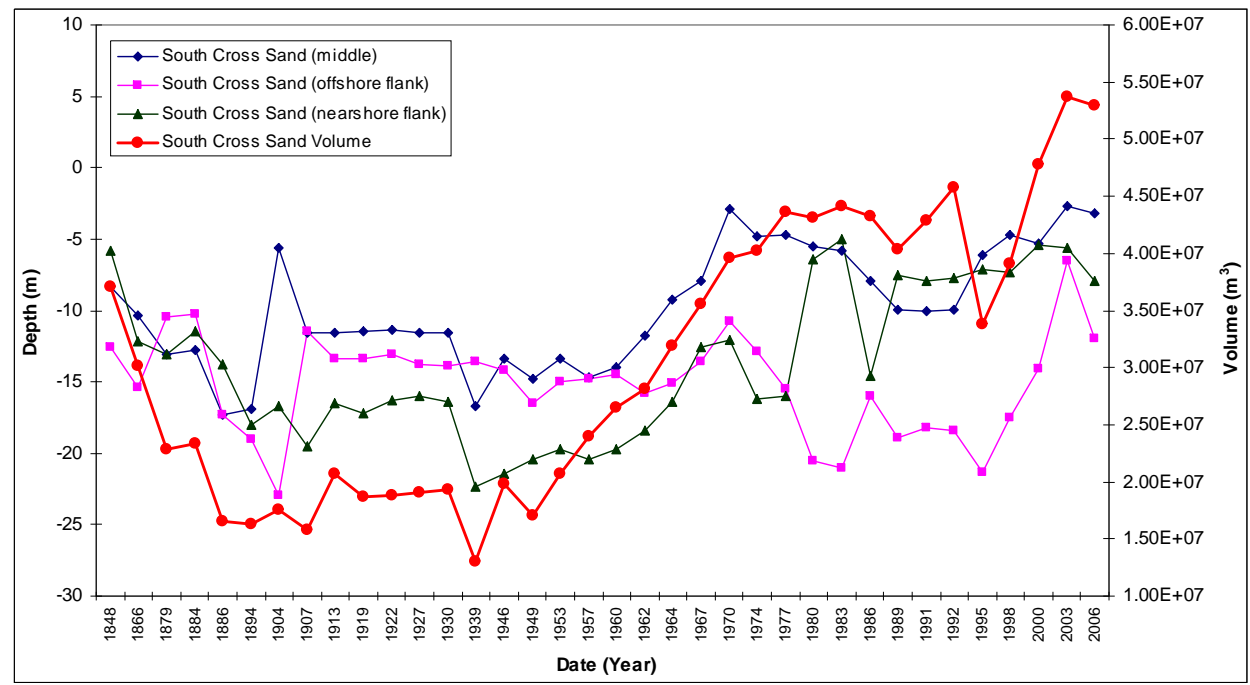

Figure 7: Time series of bed depth and sediment volume for South Cross Sand.

\section{The Roads}

The northern extent of the $15 \mathrm{~m}$ contour of The Roads is seen to be static, especially as Cockle Shoal, north of Scroby Sand links to Caister Shoal at the 10m contour through the time series (Figure 1). The southern extent of the channel at the $15 \mathrm{~m}$ contour is more variable and moves $2.5 \mathrm{~km}$ in a southerly direction through the time series. The depth variability of the assessment points is illustrated in Figure 8, which shows the offshore flank is more variable with a range of $20 \mathrm{~m}$. The offshore point is located on Yarmouth Road adjacent to Scroby Sand (Figure 2), which is known to vary laterally as described for Scroby Sand. Therefore it is most likely that the observed variation in the channel depth 
for this offshore position does relate to the migration characteristics of the sandbank. As Figure 8 suggests there is a periodic variation to the depth changes for the offshore point, with a 40-50 year period. The volume time series for the channel feature is also illustrated in Figure 8 and shows a periodic pattern in the variation. For this feature, observed volume changes coincide with depth changes for the offshore location (Figure 8). For example between 1866 and 1907 there is a decrease in the channel depth for the offshore point (Figure 8), which coincides with a decrease in sediment volume between the same dates (Figure 8). The same relationship is also repeated at a lesser magnitude between 1927 and 1949 and post 1989.

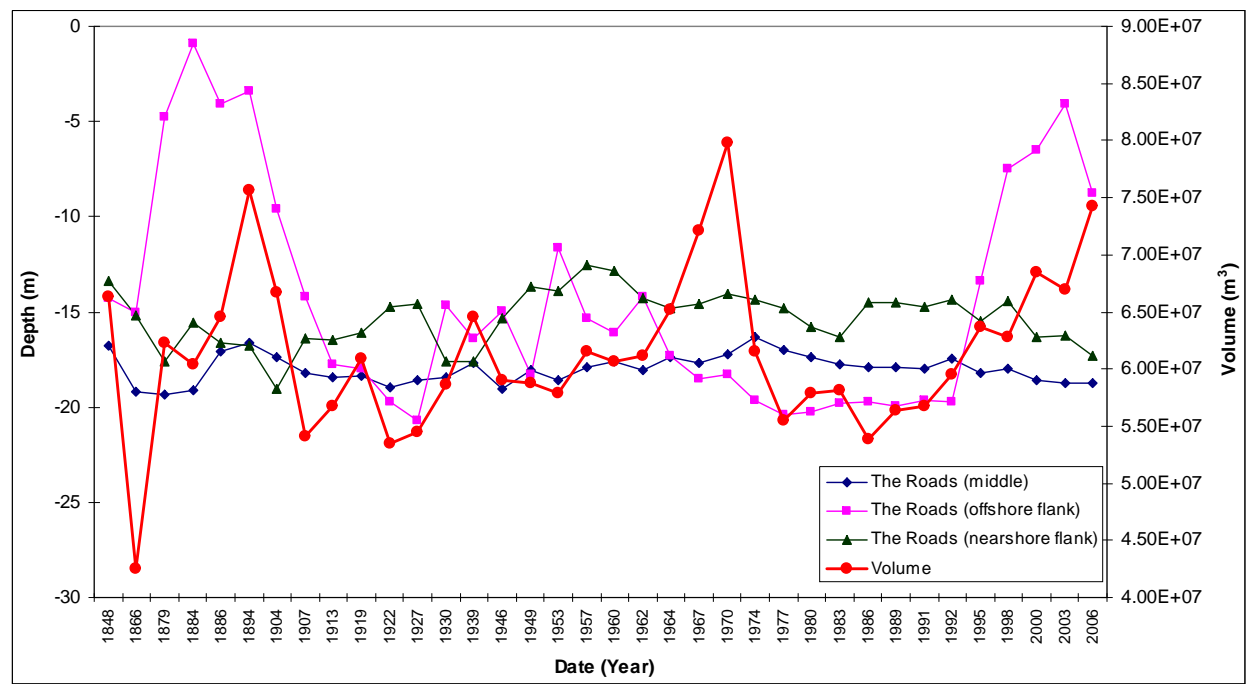

Figure 8: Time series of bed depth and sediment volume for The Roads.

\section{Barley Picle}

The assessment on the evolution of Barley Picle is carried out at the $20 \mathrm{~m}$ contour as this is a deep channel with maximum depths of up to $40 \mathrm{~m}$. At this contour the southern extent of the channel is consistent and there is little or no movement of this feature at this depth. The time series plot for a single location towards the southern extent of the channel shows that the channel varies up to a range of $10 \mathrm{~m}$ between a depth of $20 \mathrm{~m}$ and $30 \mathrm{~m}$. There is no clear periodicity in the variability of the channel at the assessed locations (Figure 9). The time series of sediment volume for this feature is set out in Figure 9. Prior to 1939 the general trend is a decrease in sediment volume. After this date a periodic pattern is seen in the increase and decrease of the sediment volume. Between 1939 and 1983, the two observed repetitions have a period of approximately 20 years; after 1983 and to the end of the dataset the period is approximately 8 years. Furthermore, superimposed on the volume fluctuation post 1940 is an overall trend of increasing sediment volumes (Figure 9). 


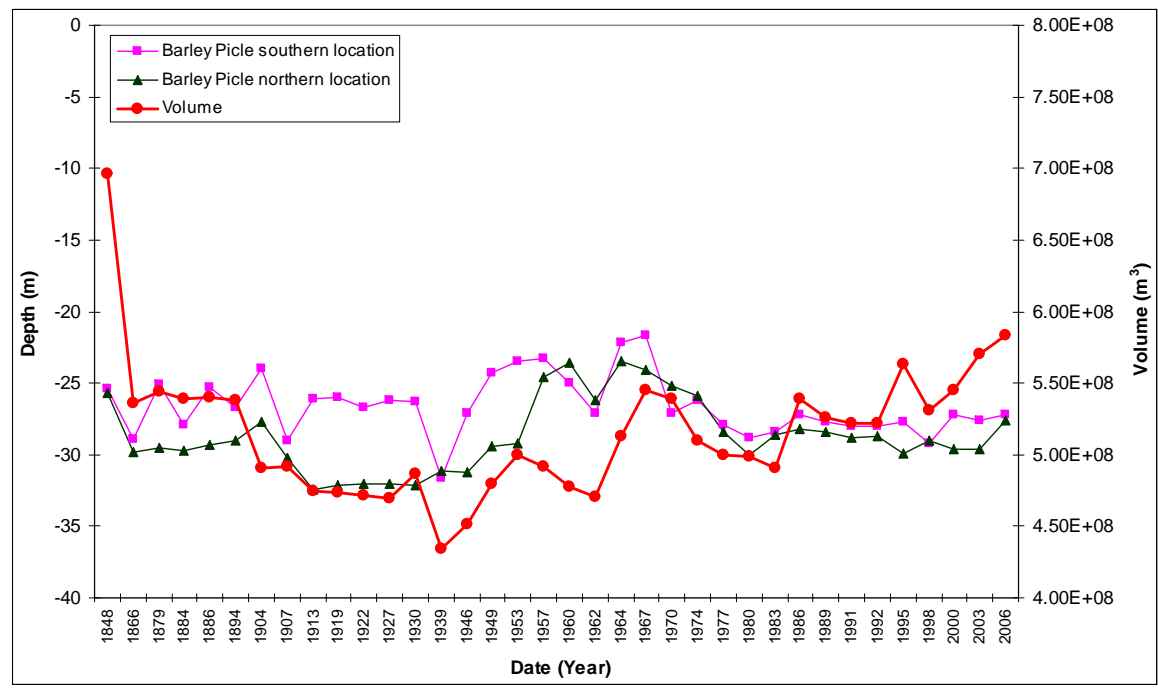

Figure 9: Time series of bed depth and sediment volume for Barley Picle.

\section{Spatial Regression Model Implementation}

To assess the validity and accuracy of the spatial regression model, it was used to generate a prediction of the surface, which was validated against observed values at the same time step. The observed, predicted and associated error surfaces are illustrated in Figure 10. Statistical measures used to assess the accuracy of the model are set out in Table 1. The Root Mean Square Error (RMSE) is compared against the observed mean bed variability, which is the mean difference in bed depths across the time steps for the whole domain. A Brier Skill Score (BSS) is also calculated, which is a dimensionless measure of predictive skill relative to the accuracy from a baseline condition, taken as the mean (Sutherland et al., 2004). Methods with good forecasting skill have scores close to one and scores close to zero are not able to provide a better estimate than the mean of the overall time series.

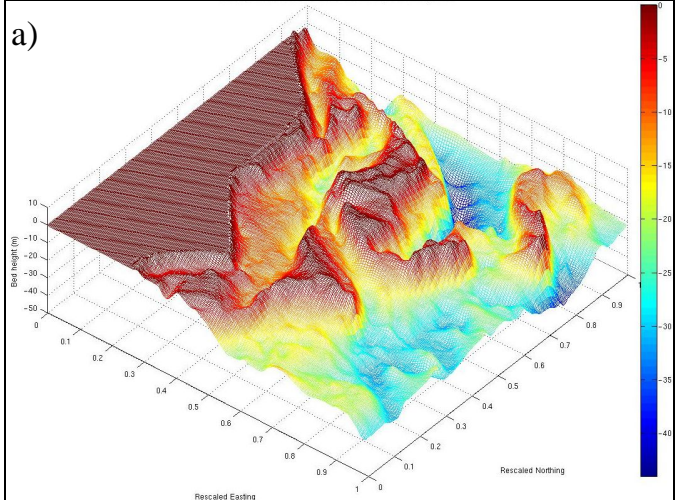

b)

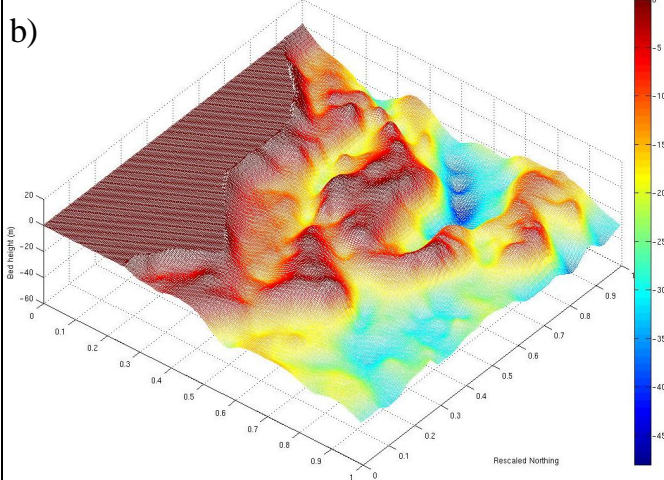

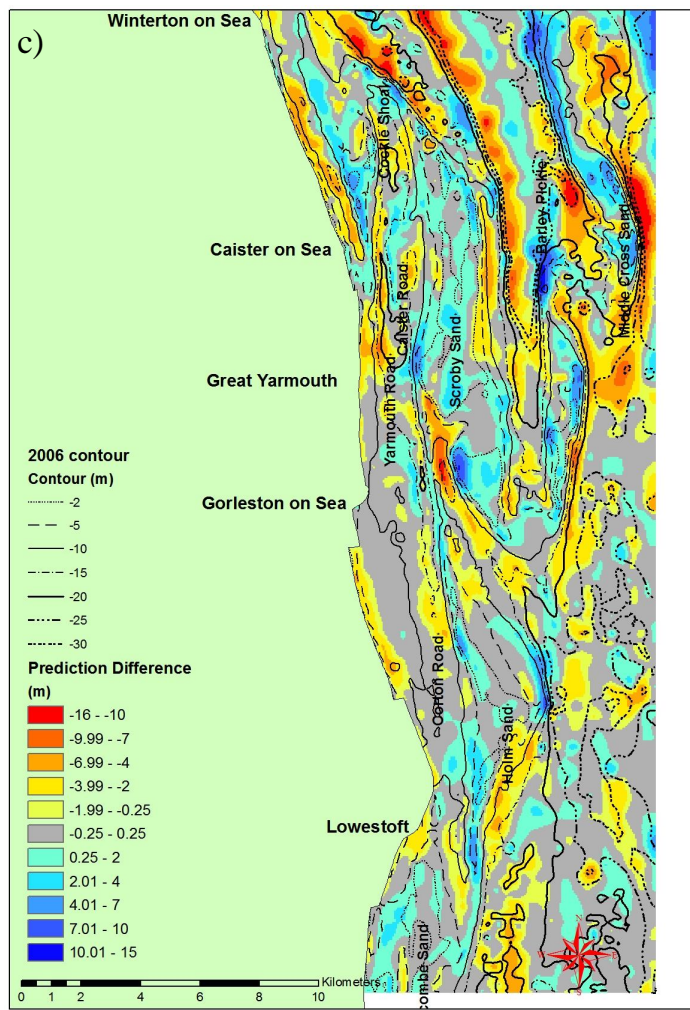

Figure 10: Model prediction results using the spatial regression model a) observed, b) predicted and c) prediction difference. 


\begin{tabular}{|l|l|l|}
\hline \multicolumn{3}{|c|}{ Table 1: Measurements of prediction accuracy and skill. } \\
\hline Mean bed variability & Root Mean Square Error $(\mathrm{m})$ & Brier Skill Score \\
\hline 2.0774 & 2.0026 & 0.5484 \\
\hline
\end{tabular}

The accuracy measures indicate that the model is able to capture bed variability and morphological behaviour using only bathymetry information. This is based on the calculated prediction error (RMSE) being less than the observed evolution patterns, with accuracies of $\pm 2 \mathrm{~m}$ across the domain. In addition, the BSS shows that the model is predicting behaviour better than simply adopting the time series mean. Figure 10c presents the distribution of prediction error across the surface. This shows that the model predicts the bed depth to an accuracy of $\pm 0.25 \mathrm{~m}$ on the top of the banks or where the gradient of the seabed is shallow. However, where there is a large change in depth over a short distance the prediction error is increased. For example on Holm Sand between the $2 \mathrm{~m}$ and $10 \mathrm{~m}$ contours there is a low prediction error, but on the flanks of Cross Sand and Barley Picle there is a large variation (Figure 10c).

\section{DISCUSSION AND CONCLUSION}

\section{Morphological Properties}

The time series of depth at the assessment points for the selected features commonly show that the greatest variability is observed on the offshore flanks. This is also represented in the standard deviation plot for the domain, where larger values are obtained on the offshore flank (Figure 11).

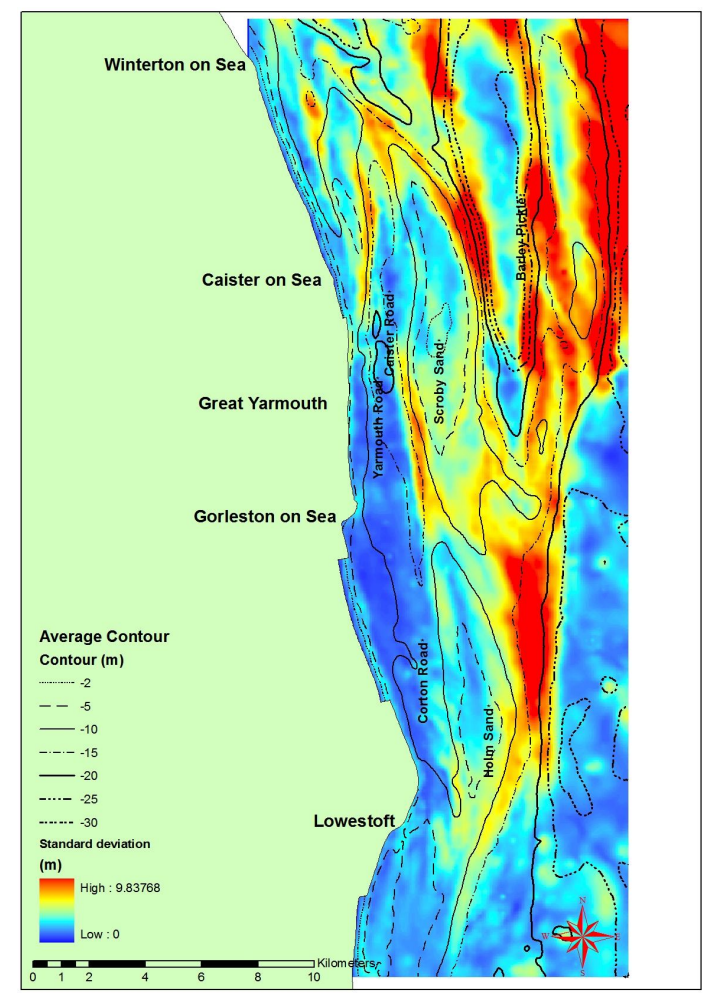

Figure 11: Calculated standard deviation

The properties of the sandbanks and channel features identified within the study are the growth, migration and periodic evolution of the sandbanks and the consistency of the channels. There is a general and consistent northward migration of the sandbank features within the domain. Although the northern extents of the banks migrate, the southern extents have not shifted at the same magnitude. Therefore the physical extent of the banks in the alongshore direction has increased between 1848 and 2006. This growth and migration of the bank features is represented in all the sandbanks. For Scroby Sand, the northern extent of the $10 \mathrm{~m}$ contour moves approximately $5 \mathrm{~km}$ in a northeast direction, whereas the southern extent moves $1 \mathrm{~km}$ to the north. The increase in the sediment volume for this feature through the time series also reflects the growth of the feature (Figure 4). During the time 
series, the northern extent of Holm Sand at the same contour moves $800 \mathrm{~m}$ to the northeast. The $10 \mathrm{~m}$ contour for North and Middle Cross Sand is also seen to migrate in a north-northeast direction for approximately $5 \mathrm{~km}$. The northern extent for South Cross Sand moves $2 \mathrm{~km}$ to the north but the southern extent moves $1 \mathrm{~km}$ to the south. The growth of the feature is again represented in the volume time series (Figure 7). The increase in the sediment volume for the bank features, particularly Scroby Sand and South Cross Sand most likely relates to growth in the spatial axes of the features. This is because the depth time series for the assessment points on the sandbank features do not demonstrate consistent decrease in depth.

The observed periodic behaviour of the sandbank features relates to the lateral movement, particularly for Scroby and North and Middle Cross Sand. For the former, the southern extent of the $10 \mathrm{~m}$ contour periodically moves onshore and offshore, in the onshore movement the feature connects with Holm Sand at the same contour. This migration is observed to have a 40-50 year cycle. North and Middle Cross Sand also demonstrate lateral migration, but it is the northern extent of this feature that periodically moves, at approximately 50-year periodicity. The lateral migration of the features is also represented in the standard deviation plot (Figure 11), in that larger variation is observed on extents of these two features. The standard deviation plot also highlights that offshore flanks of the sandbanks are more variable than the nearshore flanks. Also the depths in the middle part of the banks are seen to be fairly constant. This suggests that the central body of the banks is fixed and constant, whereas the extents and flanks of the banks evolve modifying the overall configuration. This is particularly the case for Scroby Sand and Holm Sand.

There are a number of channels within the domain. The two that are consistently present and seen to be static in position are The Roads and Barley Picle. The evaluation of these features demonstrates that spatially they are static. The depth variability observed for The Roads (Figure 8) primarily occurs on the offshore flank and is considered to relate to the changes that occur on the nearby Scroby Sand. This is because the depth time series for the offshore point has a 40-50 year periodicity as identified for Scroby Sand. This in turn influences the time series of sediment volumes observed for the channel feature (Figure 8). Barley Picle is also seen to be consistent in its spatial extent and bed depth variability, which is in turn reflected in the volume measurements for the feature (Figure 9). The channels that cross the bank features were not specifically investigated; however the assessment of the profile transect identified that these channels shift in position and alter in depth. The observed changes to these channels were seen to relate to changes in the morphology of the nearby sandbanks. For example, changes in the configuration of the banks particularly Holm Sand were observed to coincide with the emergence and disappearance of a second channel (most likely to be the intermittent Hewett Channel) crossing between Scroby Sand and Holm Sand.

Current understanding of the morphodynamic characteristics of the Great Yarmouth sandbank system is that the banks are primarily maintained by tidal currents in the area, particularly the residual currents of the dominant tide. In the study region this is a flood residual flowing northwards (Robinson, 1966). The relationship between the tidal residual and forcing remains uncertain and is still a topic under investigation. Dolphin et al., (2007) suggested that there was an interaction mechanism between the banks and channels that brought about evolution. Specifically, that changes in bank configurations in one part of the domain, indirectly led to changes in another part of the domain (Ibid.). It may be that this property exists between the evolution identified between North and Middle Cross Sand and South Cross Sand, due to the interpreted periodicity and phase from the volume time series. However, this relationship is qualitative as the covariability between the volume time series for the features is not evaluated. What is clearer is the interaction between the evolution of Scroby Sand and The Roads as described above as this is observed in the assessment of the feature depths. An anthropogenic factor that is likely to be of significance within the domain but not yet considered is dredging activity in the area. This includes both dredging to maintain navigation safety and for aggregate extraction. This factor is very likely to contribute to the variability in the observed average bed depth, because as sediment is removed or deposited in the domain, it would in turn alter feature depths. Further work would entail investigating the covariability between the morphological evolution properties and forcing conditions at a decadal scale.

\section{Model Applicability}

The results from implementing the spatial regression model in this dynamic study site indicate that it is able to identify, represent and predict real morphological properties. This conclusion is 
arrived at because the model predicts the correct form, shape and extent of the features in relation to each other and within the domain. The surface predictions for the model show that it tends to smooth out the tops and flanks of the prediction surfaces, comparing the observed and predicted surface (Figure 10a and $\mathrm{b}$ respectively). In addition the model provides better results over shallow gradients (Figure 10c). This is attributed to the resolution of the applied triangulation, which does not resolve the high frequency features. It is most likely that the small features occur at a considerably different spatial scale to the main sandbank and channel features.

Values of the observed and predicted sediment volume for the selected features using the spatial regression model are presented in Table 2. The results show that the largest percentage error margins occur for Scroby Sand, North and Middle Cross Sand and South Cross. In these instances, the prediction error margin is still less than $10 \%$ of the observed sediment volume. For the remaining features, the percentage error margin is primarily less than $1 \%$. In terms of the requirements for decadal morphodynamic analysis and coastal engineering applications the accuracy achieved may be acceptable. This is because the volume prediction error is less than $10 \%$ of the observed volume.

\begin{tabular}{|c|c|c|c|c|}
\hline Feature name (plane contour) & $\begin{array}{l}\text { Volume } \\
\text { observed }\left(\mathrm{m}^{3}\right)\end{array}$ & $\begin{array}{l}\text { Volume } \\
\text { predicted }\left(\mathrm{m}^{3}\right)\end{array}$ & $\begin{array}{l}\text { Volume } \\
\text { difference }\left(\mathrm{m}^{3}\right)\end{array}$ & $\begin{array}{l}\text { Percentage } \\
\text { difference (\%) }\end{array}$ \\
\hline Scroby Sand $(15 \mathrm{~m})$ & $311,722,627$ & $288,526,914$ & $23,195,714$ & 7.44 \\
\hline Holm Sand $(15 \mathrm{~m})$ & $169,986,788$ & $171,131,828$ & $-1,145,040$ & 0.67 \\
\hline North and Middle Cross Sand (24m) & $136,354,352$ & $148,953,522$ & $-12,599,170$ & 9.24 \\
\hline South Cross Sand $(20 \mathrm{~m})$ & $52,912,157$ & $47,675,985$ & $5,236,172$ & 9.90 \\
\hline The Roads $(24 \mathrm{~m})$ & $74,209,427$ & $73,084,047$ & $1,125,380$ & 1.52 \\
\hline Barley Picle $(45 \mathrm{~m})$ & $583,275,446$ & $577,783,157$ & $5,492,289$ & 0.94 \\
\hline
\end{tabular}

The applied model has been able to identify and correctly predict the shape, structure and form of quite complex morphological features. In addition, it has been able to generate predictions with accuracies that are less than the observed variability in the dataset. At the same time the model is able to provide good skill scores (van Rijn et al., 2003) that demonstrate it is able to identify evolution properties better than simply adopting the mean. This study site and dataset covers a $40 \mathrm{~km}$ by $10 \mathrm{~km}$ area over a 160-year period, for a complex and dynamically evolving sandbank system. Although there are errors within the predictions, these are within a margin of the observed that are potentially acceptable for macro scale morphodynamic analysis. Despite the ability of the model to derive fairly accurate predictions across the surface, the resulting statistics suggest that there is scope for improvement. The improvements in the model need to focus on locations whose depths vary quickly over short distances. It may be that these effects may be mitigated by applying a finer triangulation.

\section{ACKNOWLEDGMENTS}

The authors would like to acknowledge the support of The Crown Estate and the National Maritime Museum (NMM) for providing the opportunity to carry out the fellowship. Thank you to the data owners International Port Holdings (IPH) for making the bathymetric data available and staff at Plymouth University that provided it in its electronic form. The PhD research of the primary author is sponsored by the Engineering and Physical Sciences Research Council (EPSRC).

\section{REFERENCES}

Bakare, A., Guillas, S., Morley, J. \& Simons, R. (2009) A two-dimensional spatial statistical model for morphodynamic seabed modelling and prediction. IN Masaru, M. \& Sato, S. (Eds.) Proceedings of Coastal Dynamics 2009: Impacts of human activities on dynamic coastal processes. Tokyo, Japan, 7-11 September 2009, World Scientific. Paper 107.

Cloet, R. L. (1963) Hydrographic Analysis of the Sandbanks in the Approaches to Lowestoft Harbour. Admiralty Science Publications, Number 6. London, Hydrographic Department Admiralty.

Cooper, W. S., Townend, I. H. \& Balson, P. S. (2008) A synthesis of current knowledge on the genesis of the Great Yarmouth and Norfolk Bank Systems. The Crown Estate.

Dolphin, T. J., Vincent, C. E., Coughlan, C. \& Rees, J. M. (2007) Variability in sandbank behaviour at decadal and annual time scales and implications for adjacent beaches. Journal of Coastal Research, SI 50, 731-737. 
Dyer, K. R. \& Huntley, D. A. (1999) The origin, classification and modelling of sand banks and ridges. Continental Shelf Research, 19, 1285-1330.

Horrillo-Caraballo, J. \& Reeve, D. (2008) Morphodynamic behaviour of a nearshore sandbank system: The Great Yarmouth Sandbanks, UK. Marine Geology, 254, 91-106.

HR Wallingford (2002) Southern North Sea Sediment Transport Study Phase 2. EX 4526. Wallingford, HR Wallingford.

Huthnance, J. M. (1973) Tidal current asymmetries over the Norfolk sandbanks. Estuarine, Coastal and Shelf Science, 1, 89-99.

Huthnance, J. M. (1991) Physical oceanography of the North Sea. Ocean and Shoreline Management, 16, 199-231.

Kenyon, N., H. \& Cooper, B. (2005) Sandbanks, sand transport and offshore wind farms, Unpublished Report.

Pye, K. \& Blott, S. J. (2006) Coastal processes and morphological change in the Dunwich-Sizewell area, Suffolk, UK. Journal of Coastal Research, 22, 453-473.

Reeve, D., Li, B. \& Thurston, N. (2001) Eigenfunction Analysis of Decadal Fluctuations in Sandbank Morphology at Gt Yarmouth. Journal of Coastal Research, 17, 371-382.

Reeve, D. E., Horrillo-Caraballo, J. M. \& Magar, V. (2008) Statistical analysis and forecasts of longterm sandbank evolution at Great Yarmouth, UK. Estuarine Coastal and Shelf Science, 79, 387399.

Robinson, A. H. W. (1966) Residual currents in relation to shoreline evolution of the East Anglian coast. Marine Geology, 4, 57-84.

Stride, A. H. (1988) Indications of Long-Term Episodic Suspension Transport of Sand across the Norfolk Banks, North-Sea. Marine Geology, 79, 55-64.

Sutherland, J., Peet, A. H. \& Soulsby, R. L. (2004) Evaluating the performance of morphological models. Coastal Engineering, 51, 917-939.

Thurston, K., Vincent, C. \& Dolphin, T. (2009) Interactions between sandbanks - The Great Yarmouth Banks, UK. IN Masaru, M. \& Sato, S. (Eds.) Proceedings of Coastal Dynamics 2009: Impacts of human activities on dynamic coastal processes. Tokyo, Japan, 7-11 September 2009, World Scientific. Paper 87.

Van Rijn, L. C., Walstra, D. J. R., Grasmeijer, B., Sutherland, J., Pan, S. \& Sierra, J. P. (2003) The predictability of cross-shore bed evolution of sandy beaches at the time scale of storms and seasons using process-based Profile models. Coastal Engineering, 47, 295-327. 